\title{
PROTEKSI OCR PADA PENYULANG JERMAN GARDU INDUK MUARA DUA OKU SELATAN
}

\author{
Choirul Rizal $^{1}$, Rayhan ${ }^{2}$ \\ 1,2 Program Studi Teknik Elektro Fakultas Teknik Universitas Palembang \\ e-mail : choirulrizal1962@gmail.com
}

\begin{abstract}
ABSTRAK
Trafo adalah salah satu alat utama dalam sebuah Gardu Induk, jika terjadi suatu kegagalan pada trafo daya tidak saja menyebabkan terganggunya kontinuitas dan penyaluran daya kekonsumen, tetapi juga menyebabkan kerusakan pada peralatan listrik tersebut.

Salah satu penyebab dan mutu pelayanan dari suatu sistem tenaga listrik adalah kontinuitas pelayanannya. Kontinuitas pelayanan tenaga listrik ditentukan konstruksi sistem pengaman proteksi yang ada pada sistem tenaga listrik tersebut. Untuk menetapkan besar nilai arus gangguan dan setting dari rele dipeakai sistem simetris untuk menyelesaikan permasalahan tersebut.

Pada kasus ini dipaparkan masalah pengaman gangguan hubung singkat pada transformator daya 60 MVA 150/20 KV gardu induk Muara Dua penyulang Jerman ,yaitu pada rele proteksi arus lebih dengan menggunakan sistem simetris, dimana rele ini bekerja berdasarkan adanya kenaikan arus yang melebihi setting. Dengan dipasangnya rele arus lebih ini maka gangguan yang terasa tersebut dapat segera ditanggulangi, sehingga transformator daya dapat bekerja kembali normal dan kelangsungan penyaluran daya ke konsumen menjadi maksimal.dan besar arus gangguan sebesar 30,99 Amper dan setting waktu 0,66 detik.
\end{abstract}

\section{Kata Kunci : Gangguan Sistem, Arus Lebih, Setting Rele}

\section{PENDAHULUAN}

Transformator adalah merupakan alat vital dalam penyaluran tenaga listrik, sebab transformator adalah peralatan yang berperan menyalurkan energi listrik langsung pada konsumen baik untuk tegangan tinggi, tegangan menengah maupun tegangan rendah. Dimana sistem penyaluran tidak menutup kemungkinan akan terjadinya gangguan yang disebabkan oleh bermacam sebab, akibat. Gangguan yang sering terjadi antara lain kawat putus, kerusakan pada pembangkit, gangguan petir pada saluran transmisi dan gangguan hubung singkat.

Energi listrik ini disalurkan ke pusat-pusat beban melalui suatu sistem transmisi yang jaraknya sangat jauh. Di dalam pelaksanaan penyaluran daya listrik akan terjadi kondisi tidak normal (gangguan) yang menyebabkan terganggunya kelangsungan pelayanan energi listrik terhadap konsumen Gangguan yang dimaksud antara lain gangguan hubung singkat yang terjadi pada tranformator tenaga Gardu Induk.

Gangguan-gangguan yang tembul tersebut jika tidak dengan segera diperbaiki maka dapat merusak peralatan dan sistem tenaga listrik, seperti generator, tranformator dan peralatan listrik lainnya. Dengan demikian perlindungan peralatan sistem tenaga listrik dan bahaya gangguan yang terjadi, maka diperlukan sistem pengaman, yang harus dapat mendeteksi terjadinya gangguan serta membatasi pengaruh-pengaruh lainnya. Dengan adanya sistem pengaman tersebut maka kontinuitas pelayanan daya listrik terhadap konsumen dapat terjamin. Gangguan-gangguan yang terjadi tersebut jika tidak dengan segera diatasi maka dapat merusak peralatan dan sistem tenaga listrik, seperti 
generator, tranformator dan peralatan listrik lainnya. Dengan adanya gangguan yang tidak dapat dipridiksi maka diperlukan suatu peralatan pengaman (sistem Proteksi) yang tepat dan dapat diandalkan pada peralatan sistem tenaga listrik serta pengoperasian dan pemeliharaan yang baik. Relai proteksi harus dapat mengenal kondisi abnormal pada sistem tenaga dan melakukan langkah-langkah yang dianggap perlu untuk menjamin pemisahan gangguan dengan kemungkinan gangguan terkecil terhadap operasi normal ${ }^{(\mathbf{1}, \mathbf{3}, \mathbf{4})}$

\section{Tinjauan Pustaka}

\subsection{Menentukan Nilai Per Unit}

Besarnya tegangan, arus, KVA dan impedansi selalu dinyatakan sebagai satuan per-unit dan juga sebagai persentase pada dasar yang dipilih, semacam perhitungan sederhana. Besarnya per-unit disingkat PU, adalah perbandingan rasio antara suatu perbandingan dengan suatu besaran dasar dalam satuan yang sama'(1,2,4,5)

$$
\text { Per }- \text { Unit }=\frac{\text { Besaran yang ada }}{\text { Besaran dasar }}
$$

Perhitungan per-unit untuk sistem yang mempunyai perubahan besaran daya dan tegangan adalah sbb: ${ }^{(\mathbf{1}, \mathbf{2}, \mathbf{4 , 6})}$

$$
Z(p u)_{b a r u}=Z_{\text {diberikan }}(p u) x\left[\frac{K V_{\text {diberikan }} \text { dasar }}{K V_{\text {baru }} \text { dasar }}\right]^{2} x\left[\frac{K V A_{\text {baru }} \text { dasar }}{K V A_{\text {diberikan }} \text { dasar }}\right]
$$

\section{Menghitung Arus Dasar dalam Per-Unit digunakan persamaan :}

$$
\mathrm{I}_{\mathrm{base}}=\frac{K V A_{\text {base }}}{\sqrt{3 \times K V_{\text {base }}}}
$$

Dimana,

$\mathrm{KVA}_{\text {base }}=$ Daya dasar transformator daya $(\mathrm{KVA})$

$\mathrm{KVA}_{\text {base }}=$ Teganagn dasar transformator daya $(\mathrm{KV})$

\section{Setting Kerja Rele Arus Lebih (OCR)}

- Menghitung setting arus pada rele arus lebih

$$
\mathbf{I}_{\text {Set }}=\frac{K f k}{K d} \times \operatorname{In} \times 1 / C T
$$

Dimana,

$$
\begin{array}{ll}
\mathrm{I}_{\mathrm{Set}} & =\text { penyetelan arus } \\
\mathrm{Kfk} & =\text { Faktor keamanan }(1,1-1,2) \\
\mathrm{Kd} & =\text { Faktor perbandingan }(0,7-0,98) \\
\mathrm{In} & =\text { Arus nominal transformator (amper) }
\end{array}
$$




$$
\text { In }=\frac{K V A_{\text {base }}}{\sqrt{3 x K V_{\text {base }}}}
$$

Dimana,

$$
\begin{array}{ll}
\mathrm{KVA}_{\text {base }} & =\text { Daya dasar sistem }(\mathrm{KVA}) \\
\mathrm{KV}_{\text {base }} & =\text { Tegangan dasar transformator }(\mathrm{KV})
\end{array}
$$

- Menghitung setting waktu pada rele arus lebih

$$
\operatorname{Tms}=\frac{t x\left|\frac{I_{r}}{I_{\text {setting }}}\right|^{0,02}-1}{0,14}
$$

Dimana,

$$
\begin{array}{ll}
\mathrm{T} & =\text { Waktu settting terpasang pada rele arus lebih (Detik) } \\
\mathrm{I}_{\text {setting }} & =\text { Setting arus hasil perhitungan (Amper) } \\
\mathrm{I}_{\mathrm{r}} & =\text { Arus gangguan pada transformator (Amper) }
\end{array}
$$

\section{Metodologi}

Adapun metode yang digunakan dalam penelitian merupakan lagkah-langkah yang ditempuh sebagai bahan kajian pada bab selanjutnya, selain disesuaikan dengan metode penelitian yang akan digunakan, cara-cara pengumpulan data yang harus dipenuhi tujuan penelitian yaitu menganalisa penerapan teori penunjang sebagai pembuktian kebenarannya.

1. Studi literatur Melalui pembahasan dengan literatur yang ada yang berkaitan dengan tema penelitian.

2. Studi Lapangan yaitu dengan mengumpulkan data-data yang diperlukan dalam proses untuk penelitian, dimana metode ini yang digunakan pada penelitian yang dilakukan, dengan mengumpulkan data, lalu mengklarifikasikannya, mengolah data yang didapat, mendapatkan hasil yang diinginkan, lalu dianalisa dan terakhir dirumuskan untuk diambil kesimpulan.

\section{Hasil dan Pembahasan.}

\subsection{Data Jaringan Penyulang Jerman}

Untuk mendapatkan nilai arus gangguan hubung singkat perlu dilakukan perhitungan dengan mengacu data yang ada pada jaringan $20 \mathrm{KV}$ Trafo 150/20 KV 60 MVA di GI Muara Dua dengan panjang saluran dari sisi sekunder Trafo ke sel incoming $20 \mathrm{KV}$ 8,3 Km dan impedansi Trafo sebesar $8,3 \%$.

\subsubsection{Data Transformator}

$$
\text { Lokasi }
$$

Gardu Induk Muaradua 
Merek

Kapasitas

Impedansi $(\%)$

Tegangan

\section{ENERGOIN VEST}

60 MVA

$8,3 \%$

$150 / 20 \mathrm{KV}$

\subsubsection{Data Saluran}

Saluran Gardu Induk Muaradua kepenyulang Jerman

Panjang penghantar $8,3 \mathrm{Km}$

$\mathrm{Z}=(\mathrm{R}+\mathrm{j} \mathrm{X}) \mathrm{x}$ panjang saluran

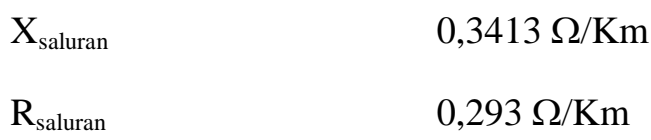

Zsaluran $=(0,293+\mathrm{j} 0,3413) \times 8,3 \mathrm{Km}$

$\mathrm{Z}$ saluran $=(2,4319+\mathrm{j} 2,8328) \mathrm{ohm}$

Impedansi Dasar $=\frac{(K V)^{2}}{M V A}=\frac{(20)^{2}}{60}=6,7 \mathrm{Ohm}$

$\operatorname{Jadi} Z(p u)=\frac{2,4319+j 2,8328}{6,7}=(0,3630+\mathrm{J} 0,4228) \mathrm{pu}$

I dasar $=\frac{60 M V A}{\sqrt{3} \times 20 K V}=1732,10$ Amper

\subsubsection{Data Rele Arus Lebih (OCR)}

$\begin{array}{ll}\text { Merek } & : \text { ISKRA } \\ \text { Jumlah } & : 1 \\ \text { Arus Setting } & : 1 \text { Amper } \\ \text { Waktu Setting } & : 1 \text { Detik } \\ \text { Rasio CT } & : 300 / 5 A \\ \text { Kfk (Faktor Keamanan) } & : 1,1 \\ \text { Kd (Faktor Arus Kembali) } & : 0,95 \\ \text { PMT, VCB } & : 630 \text { Amper, 25 KA }\end{array}$

\subsubsection{Perhitungan Impedansi total}

Dari sistem yang ditinjau :

Proteksi OCR pada Penyulang Jerman Gardu Induk Muara Dua OKU Selatan 


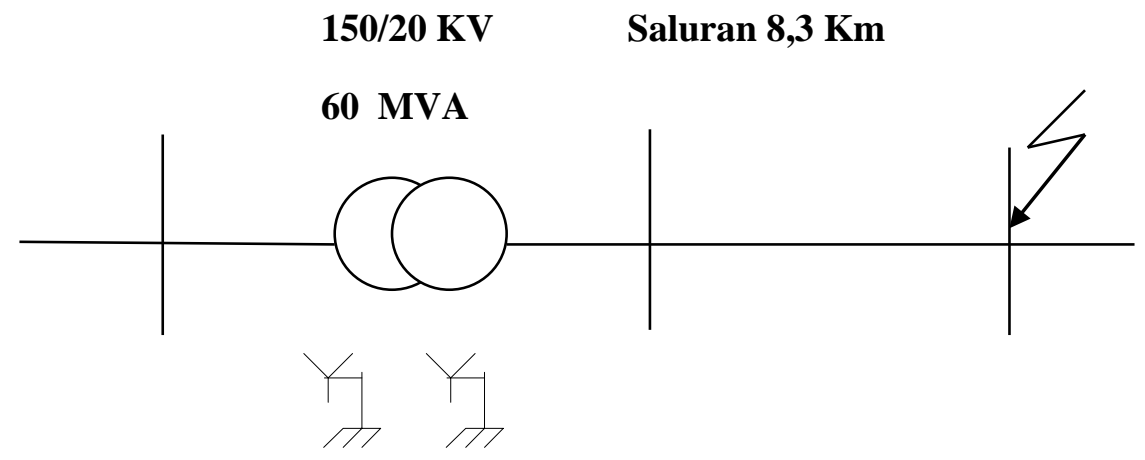

Gambar.1. Diagram Segaris Penyulang jerman

Dimana Impedansi Trafo adalah :

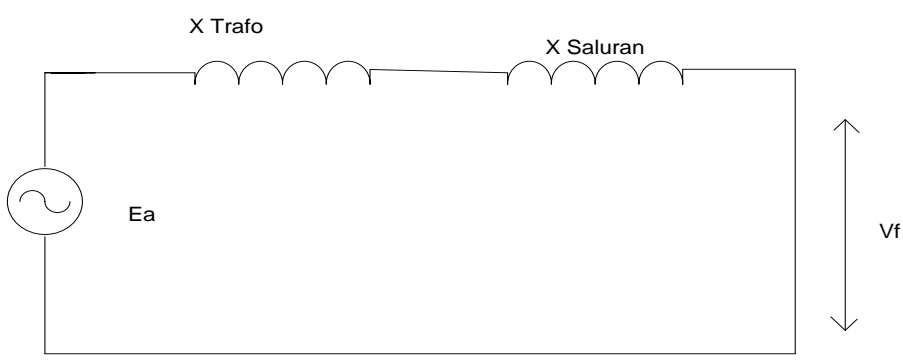

Gambar 2. Reaktansi Urutan Positip

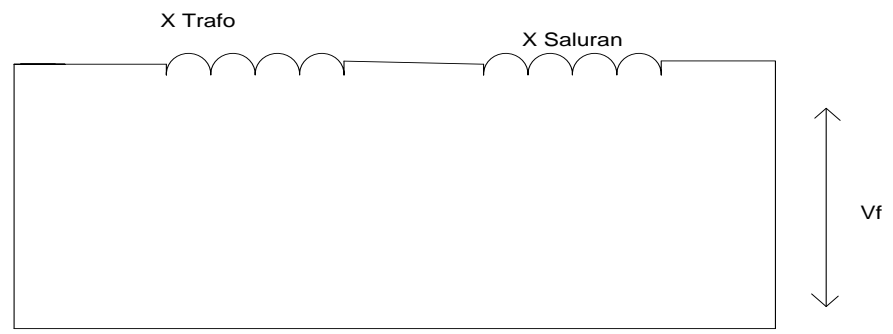

Gambar.3. Reaktansi urutan Negatip

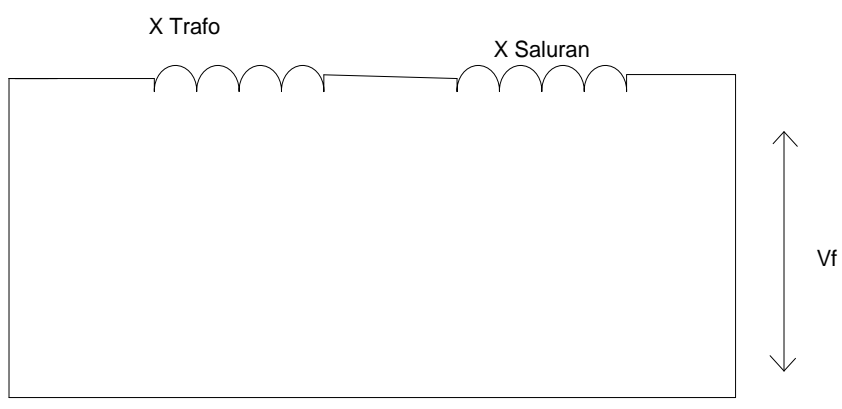

Gambar .4. Diagram Reaktansi urutan Nol

$Z_{\text {trafo }}=0,083\left[\frac{K V_{\text {lama }}}{K V_{\text {barur }}}\right]^{2}\left[\frac{M V A_{\text {baru }}}{M V A_{\text {lama }}}\right]=0,083\left[\frac{20}{20}\right]^{2}\left[\frac{60}{60}\right]=\mathbf{0 , 0 8 3} \mathbf{~ p u}$

$\mathrm{Z}$ total $=\mathrm{Z}$ trafo $+\mathrm{Z}$ saluran $=0,083+(0,3630+\mathrm{J} 0,4228=(0,4460+\mathrm{j} 0,4228) \mathrm{pu}$ 
Jadi impedansi urutan positif sama dengan impedansi urutan negati $=(0,4460+\mathrm{J} 0,4228) \mathrm{pu}$, karena sistem transformator diketanahkan langsung maka dengan demikian impedansi urutan Nol nya adalah sama juga dengan impedansi urutan positif dan negatif.

\subsection{Perhitungan Arus Gangguan}

Perhitungan besar arus hubung singkat pada transformator daya 60 MVA 150/20 Kvdi Gardu Induk Muaradua Oku ini, gangguan terjadi pada sisi $20 \mathrm{KV}$. Dengan memasukan harga-harga impendansi total urutan jala-jala dari sistem maka dapat kita hitung besar arus hubung singkat.

\subsubsection{Gangguan Hubung Singkat yang Terjadi.}

\section{Arus Gangguan Satu Fasa}

$$
\begin{aligned}
& I_{h s 1 \Phi}=\frac{3 \cdot E}{Z_{1}+Z_{2}+Z_{o}}, \text { karena trafo ditanahkan langsung maka } \mathrm{Z} 1=\mathrm{Z} 2=\mathrm{Zo}, \text { maka } \\
& I_{h s 1 \Phi}=\frac{3 \cdot E}{3 \cdot(0,4460+j \cdot 0,4228))}=\frac{1 \angle 0^{0}}{0,62 \angle 43,47^{0}}=1,61 \angle-43,47^{0} \mathrm{pu} \\
& I f_{h s 1 \Phi}=1,61 x 1732,10=2788,68 \text { Amper }
\end{aligned}
$$

\section{Arus Gangguan Dua Fasa :}

$$
\begin{aligned}
I_{h s 2 \Phi} & =\frac{\sqrt{3} \cdot V_{f}}{Z_{1}+Z_{2}}=\frac{\sqrt{3} \cdot(1+j \cdot 0)}{(0,4460+j \cdot 0,4228)+(0,4460+j \cdot 0,4228)}=\frac{1,73 \angle O^{0}}{0,67 \angle 43,47^{0}} \\
& =2,58 \quad \angle-43,47^{0} \\
I F_{2 \Phi} & =2,58 x 1732,10=4468,82 \text { Amper }
\end{aligned}
$$

\section{Arus Gangguan Tiga Fasa:}

$$
\begin{aligned}
& I_{h s 3 \Phi}=\frac{V_{f}}{Z_{1}}=\frac{(1+j .0)}{(0,4460+j .0,4228)}=\frac{1 \angle O^{0}}{0,62 \angle 43,47^{0}}=1,61 \angle-43,47^{0} \\
& I F_{3 \Phi}=1,61 x 1732,10=2788,68 \text { Amper }
\end{aligned}
$$

\subsection{Penyetelan Rele Arus Lebih (OCR)}

$$
I_{s e t}=\frac{I_{h s}}{K_{s}}
$$

\section{Dimana,}

$$
\begin{aligned}
& I_{\text {set }}=\text { Arus hubung singkat } \\
& K_{s}=1,5
\end{aligned}
$$




\section{Setting Gangguan Arus Hubung Singkat Satu Fasa :}

$$
\begin{gathered}
I_{\text {set }}=\frac{I_{h s} 1 \Phi}{K_{s}}=\frac{2788,68}{1,5}=1859,12 \\
I_{n}=\frac{1859,12}{300 / 5}=30,99 \text { Amper } \\
I_{\text {instan }}=30,99 . . I_{n}
\end{gathered}
$$

Setting waktu kerja rele arus lebih adalah sebesar :Karena rele di stel pada waktu, $t=1$ detik, maka pengali waktu (Tms) adalah :

$\operatorname{Tms}=\frac{\operatorname{tx}\left|\frac{I_{1 \Phi}}{I_{\text {sett }}}\right|^{0,02}-1}{0,14}=\frac{1 x\left|\frac{2788,68}{30,99}\right|^{0,02}-1}{0,14}=0,66 \mathrm{detik}$

\section{Setting Gangguan Arus Hubung Singkat Dua Fasa :}

$$
\begin{gathered}
I_{\text {set }}=\frac{I_{h s} 2 \Phi}{K_{s}}=\frac{4468,82}{1,5}=2979,21 \\
I_{n}=\frac{2979,21}{300 / 5}=49,65 \text { Amper } \\
I_{\text {ins } \tan }=49,65 . . I_{n}
\end{gathered}
$$

Setting waktu kerja rele arus lebih adalah sebesar :Karena rele di stel pada waktu, $\mathrm{t}=1$ detik, maka pengali waktu (Tms) adalah :

Tms $=\frac{\operatorname{tx}\left|\frac{I_{2 \Phi}}{I_{\text {sett }}}\right|^{0,02}-1}{0,14}=\frac{1 x\left|\frac{4468,82}{49,65}\right|^{0,02}-1}{0,14}=0,67$ detik

\section{Setting Gangguan Arus Hubung Singkat Tiga Fasa :}

$$
\begin{gathered}
I_{\text {set }}=\frac{I_{h s} 3 \Phi}{K_{s}}=\frac{2788,68}{1,5}=1859,12 \\
I_{n}=\frac{1859,12}{300 / 5}=30,99 \text { Amper } \\
I_{\text {instan }}=30,99 . . I_{n}
\end{gathered}
$$


Setting waktu kerja rele arus lebih adalah sebesar :Karena rele di stel pada waktu, $t=1$ detik, maka pengali waktu (Tms) adalah :

$\operatorname{Tms}=\frac{\operatorname{tx}\left|\frac{I_{3 \Phi}}{I_{\text {sett }}}\right|^{0,02}-1}{0,14}=\frac{1 x\left|\frac{2788,68}{30,99}\right|^{0,02}-1}{0,14}=0,66 \mathrm{detik}$

\section{Penutup}

Dari hasil analisa dan perhitungan terhadap gangguan pada transformator daya 60 MVA 150/20 $\mathrm{KV}$, besar setting arus hubung singkat adalah sebesar 30,99 Amper pada waktu 0,66 detik

\section{DAFTAR PUSTAKA}

1.B.M. Weedy, "Sistem Tenaga Listrik", Aksara Persadalndonesia, 1978.

2,Dipi. Renaldo Zoro., "Proteksi Sistem Tenaga”, Diktat Kuliah bagian 2 ITB, 1987.

3.Bonar Pandjaitan, ” Proteksi Sistem Tenaga Listrik” Andy Jogjakarta, 2012

4.Cek Mas Cekdin,” Sistem Tenaga Listrik” Andy Jogjakarta, 2007

5.Djiteng Marsudi,’ Pembangkitan Energi Listrik ” Erlangga Jakarta,2002

6.T.S. Hutauruk.K.M.E.E., “Analisa Sistem Tenaga Listrik”, Diktat Kuliah Jilid 1 dan 2 Departemen Elektronik ITB, 1979. 